\title{
Nucleobase assemblies supported by uranyl cation coordination and other non-covalent interactions
}

\author{
JITENDRA KUMAR and SANDEEP VERMA* \\ Department of Chemistry, Indian Institute of Technology Kanpur, Kanpur 208016, India \\ e-mail: sverma@iitk.ac.in
}

\begin{abstract}
We describe synthesis and solid state structural description of uranyl complexes of carboxylate functionalized adenine and uracil derivatives. The metal coordination through carboxylate pendant leads to the formation of dimeric assemblies, whereas the directional nature of hydrogen bonding interaction supported by nucleobases and aqua ligands, result in the generation of complex 3-D architectures containing embedded nucleobase ribbons.
\end{abstract}

Keywords. Adenine ribbon; uracil tetrad; uranyl complex; hydrogen bonding.

\section{Introduction}

Metal ion coordination and the use of non-covalent interactions, such as hydrogen bonding and $\pi-\pi$ stacking, are commonly employed to design inorganicorganic hybrid materials using smaller building blocks, which can be tuned for directionality of interaction and provide a scope of maximizing non-covalent interactions. ${ }^{1-24}$ The supramolecular architectures generated from such ligands, at times decorated with suitable functionalities that further support metal-coordination and hydrogen bonding interactions, simultaneously, is of great relevance in achieving structural complexity. Thus, it is realized that the possibility of invoking more than one stabilizing interaction in a premeditated fashion ensures significant advantages over pure coordination polymers and affords versatile entry into interesting topologies. ${ }^{25-37}$

Heterocyclic nucleobases blend the possibility of stable metal ion coordination, while offering biologically relevant hydrogen bonding sites that could be eventually used for interactions with other biological macromolecules. ${ }^{38,39}$ Thus, the use of nucleobases has indeed emerged as a much pursued area of research in bioinorganic chemistry. ${ }^{40,41}$ We have a long-standing interest to explore metal coordination and hydrogen bond-

${ }^{*}$ For correspondence ing capability of adenine nucleobases, for generating novel complex structures with interesting photophysical properties, for direct patterning of crystal structures on designed surfaces for AFM measurements and for achieving catalysis of certain chemical and biochemical reactions. ${ }^{42-47}$ Recently, we have chemically attached nucleobases, such as adenine or uracil, to modify single-walled carbon nanotubes with coordinating ligands that can further interact with metal ions to reveal a new class of metalized nanotubes, with possible catalytic applications. ${ }^{48-50}$

In continuing our efforts to combine metal coordination and hydrogen bonding strategies, we studied crystallographic signatures of two nucleobase derivatives bearing carboxyl pendant: namely, 3-(N9-adeninyl) propanoic acid(HL1) and 3-(N1-uracilyl) propanoic acid (HL2) with uranyl cations $\left(\mathrm{UO}_{2}\right)^{2+}$. Uranyl(VI) cations are known as hard Lewis acid centers and demonstrate selectivity for O-donors, ${ }^{51-54}$ as suggested by numerous reports concerning uranyl-carboxylate or polycarboxylate frameworks. ${ }^{55-64}$ Moreover, hybrid materials based on $\mathrm{U}(\mathrm{VI})$ metal center offer interest in terms of their unique properties and potential application in the areas associated with optics, magnetism, ion exchange and catalysis. ${ }^{65}$ There are some instances where uranyl complexes have been used for catalysis of certain reactions. ${ }^{66-71}$ In this context, we have demonstrated sunlight-mediated photolytic cleavage of nucleic acids by coordinated uranyl cations. ${ }^{72}$ Another aspect of the study deals with the bio-coordination chemistry of $\mathrm{U}(\mathrm{VI})$ ions. ${ }^{73}$ This paper aims to discuss the structural consequences observed for uranyl complexes of two nucleobase derivatives as shown in scheme 1 . 
<smiles>Nc1ncnc2c1ncn2CCC(=O)O</smiles>

HL1<smiles>O=C(O)CCn1ccc(=O)[nH]c1=O</smiles>

HL2
Scheme 1. Molecular structure of HL1 and HL2 ligands bearing carboxyl pendant.

\section{Experimental}

Caution! With uranium being a radioactive and chemically toxic element, uranium-containing samples must be handled with suitable care and protection.

2.1 Synthesis of 3-(N9-adeninyl) propanoic acid (HL1) and 3-(N1-uracilyl) propanoic acid (HL2)

The synthesis and characterization of the ligands $\mathbf{H L 1}^{47}$ and $\mathbf{H L 2}^{48}$ used in the present study has already been discussed in our previous publications.

\subsection{Synthesis of complex $1\left[C_{16} H_{24} N_{10} O_{10} U\right.$ ]}

HL1 (100 mg, 1.0 eq.), $\mathrm{UO}_{2}\left(\mathrm{NO}_{3}\right)_{2} \cdot 6 \mathrm{H}_{2} \mathrm{O}(121 \mathrm{mg}$, 0.5 eq.) and demineralized water $(5 \mathrm{~mL})$ were placed in a $10 \mathrm{~mL}$ Teflon liner stainless steel bomb and heated at $120^{\circ} \mathrm{C}$ for 5 days under autogenous pressure which afforded light yellow crystals of complex 1 . The product was recovered after filtration and washed with water ( $80 \mathrm{mg}, 44 \%$ yield, based on U(VI) precursor). HRMS (ES+ mode): For complex $\mathbf{1}\left[2 . \mathbf{L} \mathbf{1}+\mathrm{UO}_{2}+\mathrm{H}\right]^{+}=$calculated: 683.1840 , found: 683.1843 .

\subsection{Synthesis of complex $2\left[\mathrm{C}_{14} \mathrm{H}_{18} \mathrm{~N}_{4} \mathrm{O}_{12} \mathrm{U}\right]$}

HL2 (100 mg, 1.0 eq.), $\mathrm{UO}_{2}\left(\mathrm{NO}_{3}\right)_{2} \cdot 6 \mathrm{H}_{2} \mathrm{O}(136 \mathrm{mg}$, 0.5 eq.) and demineralized water $(5 \mathrm{~mL})$ were placed in a tightly closed $10 \mathrm{~mL}$ Teflon liner and heated at $100^{\circ} \mathrm{C}$ for $48 \mathrm{~h}$ under autogenous pressure which resulted in a clear light yellow solution. The solution was filtered and kept for slow evaporation which afforded block shape crystals of complex $\mathbf{2}$ after two week period
(55 mg, 30\% yield, based on U(VI) precursor). For complex 2 [2.L2 $\left.+\mathrm{UO}_{2}+\mathrm{H}\right]^{+}=$calculated: 637.1296, found: 637.1295 .

\subsection{Crystal structure determination and refinement}

Crystals were coated with light hydrocarbon oil and mounted in the $100 \mathrm{~K}$ dinitrogen stream of a Bruker SMART APEX CCD diffractometer equipped with CRYO Industries low-temperature apparatus and intensity data were collected using graphite-monochromated Mo-K $\alpha$ radiation. The data integration and reduction were processed with SAINT software. ${ }^{74}$ An absorption correction was applied. ${ }^{75}$ Structures were solved by the direct method using SHELXS-97 and refined on $F^{2}$ by a full-matrix least-squares technique using the SHELXL-97 program package. ${ }^{76}$ Non-hydrogen atoms were refined anisotropically. In the refinement, hydrogens were treated as riding atoms using the SHELXL default parameters, however for the water molecules in both the crystal structures, the hydrogen atoms were located on Fourier map and refined freely though DFIX constrain were applied to fix the $\mathrm{O}-\mathrm{H}$ distance.

\section{Results and discussion}

Block shape yellow coloured crystals of complex $\mathbf{1}$ $\left[\mathrm{C}_{16} \mathrm{H}_{24} \mathrm{~N}_{10} \mathrm{O}_{10} \mathrm{U}\right]$ and $2\left[\mathrm{C}_{14} \mathrm{H}_{18} \mathrm{~N}_{4} \mathrm{O}_{12} \mathrm{U}\right]$ were obtained via hydrothermal reaction by dissolving stoichiometric amounts of uranyl nitrate hexahydrate and HL1 or HL2 as described in the experimental section. X-ray crystallographic analysis revealed that complex $\mathbf{1}$ crystallized in a monoclinic space group $C 2 / c$, whereas complex 2 crystallized in a triclinic space group ' $P-1$ '. The asymmetric unit in both the cases consisted of a $\mathrm{UO}_{2}^{+2}$ ion of half-occupancy neutralized by either $\mathbf{L 1}$ or $\mathbf{L} \mathbf{2}$ anion, along with two and one water molecule, respectively (figure 1). The crystal structure refinement parameters for both the complexes are given in table 1 .

Both of these complexes are zero-dimensional and exhibit formation of coordination complexes with a $1: 2$ M:L stoichiometry as shown in figure 1 , where $\mathrm{U}(\mathrm{VI})$ center is connected to eight oxygen atoms and leading to a distorted hexagonal bipyramid geometry for U(VI) center. The axial sites of this hexagonal bipyramid are occupied by doubly bonded oxo ligands (namely $\mathrm{O} 3$ and $\mathrm{O} 4$ in case of $\mathbf{1}$; O5 and its symmetry equivalent in case of 2) with a shorter bond length and a linear $\mathrm{O}=\mathrm{U}=\mathrm{O}$ bond angle. The remaining four oxygen atoms are contributed by a pair of carboxylate group coordinated in bidentate chelate mode (O1, O2 and their symmetry equivalents in case of $\mathbf{1} ; \mathrm{O} 3, \mathrm{O} 4$ and their 
(a)
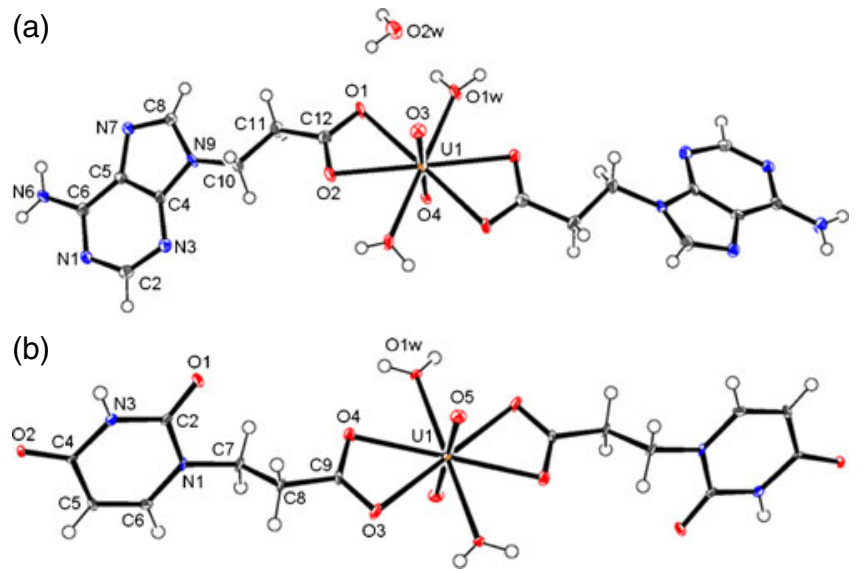

Figure 1. Molecular structure of complexes at 50\% probability level with labelling of unique atoms: (a) for complex 1, and (b) for complex 2. Bond distances (in $\AA$ ) for 1: $\mathrm{U}-\mathrm{O} 1=2.494(3), \mathrm{U}-\mathrm{O} 2=2.490(3), \mathrm{U}-\mathrm{O} 3=1.785(4)$, $\mathrm{U}-\mathrm{O} 4=1.741(4), \mathrm{U}-\mathrm{O} 1 \mathrm{~W}=2.438(3)$ and for 2 : $\mathrm{U}-\mathrm{O} 3=$ 2.473(6), U-O4=2.479(6), U-O5=1.771(6), U-O1W= $2.470(6)$ symmetry equivalents in case of 2). Two $\mathrm{C}-\mathrm{O}$ bond lengths of carboxylate groups are nearly equivalent being consistent with its binding mode $\left(\eta-\mathrm{O}, \mathrm{O}^{\prime}\right)$. The remaining two oxygen atoms are attributed to aqua ligands (O1W and its symmetry equivalents). Together, these six atoms make a hexagonal equatorial plane of the polyhedra around $\mathrm{U}(\mathrm{VI})$ center (see figure 1 caption for detailed bond geometries; selected bond lengths and bond angles for both the complexes are summarized in table 2). Interestingly, in complex 1, an extra water molecule $(\mathrm{O} 2 \mathrm{~W})$ is found trapped in the lattice as solvent of crystallization. The U(VI) atom in complex 1 lies on two-fold rotational axis along $\mathrm{O}=\mathrm{U}=\mathrm{O}$ bond, whereas in case of $\mathbf{2}$ it lies on the center of inversion.

Although, crystal lattice of both complexes consist only of $\mathrm{L}-\mathrm{M}-\mathrm{L}$ species, it is important to investigate the interaction of these basic units in the crystal lattice. The extended network of highly ordered H-bond connections, due to the presence of potential complementary hydrogen bonding sites like nucleobase moiety and $\mathrm{H}_{2} \mathrm{O}$ molecules, give rise to complex 3-D frameworks that are worthy of detailed discussion. The important

Table 1. Crystal structure refinement parameters for the complexes $\mathbf{1}$ and $\mathbf{2}$.

\begin{tabular}{|c|c|c|}
\hline Identification code & Complex 1 & Complex 2 \\
\hline Empirical formula & $\mathrm{C}_{16} \mathrm{H}_{24} \mathrm{~N}_{10} \mathrm{O}_{10} \mathrm{U}$ & $\mathrm{C}_{14} \mathrm{H}_{18} \mathrm{~N}_{4} \mathrm{O}_{12} \mathrm{U}$ \\
\hline$M \mathrm{r}$ & 754.48 & 672.35 \\
\hline Crystal system & Monoclinic & Triclinic \\
\hline Space group & $C 2 / c$ & $P-1$ \\
\hline$a / \AA$ & $26.7030(4)$ & $7.122(3)$ \\
\hline$b / \AA$ & $7.0740(2)$ & $8.426(4)$ \\
\hline$c / \AA$ & $13.7080(4)$ & $8.469(4)$ \\
\hline$\alpha /^{\circ}$ & 90 & $79.253(4)$ \\
\hline$\beta /{ }^{\circ}$ & $119.405(2)$ & $79.751(5)$ \\
\hline$\gamma /{ }^{\circ}$ & 90 & $70.624(3)$ \\
\hline Volume $/ \AA^{3}$ & $2255.81(10)$ & $467.3(4)$ \\
\hline Z & 4 & 1 \\
\hline$D x / \mathrm{Mg} \mathrm{m}^{-3}$ & 2.222 & 2.389 \\
\hline$F(000)$ & 1448 & 318 \\
\hline$\mu / \mathrm{mm}^{-1}$ & 7.274 & 8.761 \\
\hline$\theta$ range for data collection $/^{\circ}$ & $\begin{array}{l}4.22 \text { to } 25.03 \\
-26 \rightarrow h \rightarrow 31\end{array}$ & $\begin{array}{l}2.59 \text { to } 25.34 \\
-8 \rightarrow h \rightarrow 4\end{array}$ \\
\hline Limiting indices & $\begin{array}{l}-8 \rightarrow \mathrm{k} \rightarrow 6 \\
-16 \rightarrow 1 \rightarrow 15\end{array}$ & $\begin{array}{l}-10 \rightarrow \mathrm{k} \rightarrow 9, \\
-10 \rightarrow 1 \rightarrow 9\end{array}$ \\
\hline Reflections collected & 5482 & 2429 \\
\hline Unique reflections & 1994 & 1662 \\
\hline$R$ (int) & 0.0387 & 0.0212 \\
\hline Completeness to $\theta$ & $=25.03,99.4$ & $=25.34,97.3 \%$ \\
\hline Data/restraints/parameters & $1994 / 4 / 181$ & $1662 / 2 / 138$ \\
\hline Goodness-of-fit on $F^{2}$ & 1.097 & 1.339 \\
\hline$R 1$ and $R 2[I>2 \sigma(I)]$ & $0.0248,0.0569$ & $0.0324,0.0976$ \\
\hline$R 1$ and $R 2$ (all data) & $0.0284,0.0586$ & $0.0343,0.1065$ \\
\hline Largest diff. peak and hole/e. $\AA^{-3}$ & 1.563 and -1.182 & 1.853 and -2.913 \\
\hline
\end{tabular}


Table 2. Selected U-O bond lengths and $\mathrm{O}-\mathrm{U}-\mathrm{O}$ bond angles for complex $\mathbf{1}$ and 2."

\begin{tabular}{|c|c|c|c|c|c|}
\hline \multicolumn{2}{|c|}{ Bond lengths $(\AA)$} & \multicolumn{4}{|c|}{ Bond angles $\left({ }^{\circ}\right)$} \\
\hline Complex 1 & & & & & \\
\hline U1-O1 & $2.494(3)$ & $\mathrm{O} 1-\mathrm{U} 1-\mathrm{O} 1^{i}$ & $176.27(15)$ & $\mathrm{O} 2-\mathrm{U} 1-\mathrm{O} 3$ & $89.34(7)$ \\
\hline $\mathrm{U} 1-\mathrm{O} 1^{i}$ & $2.494(3)$ & $\mathrm{O} 1-\mathrm{U} 1-\mathrm{O} 2^{i}$ & $128.35(10)$ & O2-U1-O4 & $90.66(7)$ \\
\hline $\mathrm{U} 1-\mathrm{O} 2$ & $2.490(3)$ & O1-U1-O2 & $51.70(10)$ & O2-U1- O1W & $115.73(11)$ \\
\hline $\mathrm{U} 1-\mathrm{O} 2^{i}$ & $2.490(3)$ & $\mathrm{O} 1-\mathrm{U} 1-\mathrm{O} 3$ & $91.86(7)$ & $\mathrm{O} 2-\mathrm{U} 1-\mathrm{O} 1 \mathrm{~W}^{i}$ & $64.28(11)$ \\
\hline U1-O3 & $1.785(4)$ & O1-U1-O4 & $88.14(7)$ & O3-U1-O4 & $180.000(2)$ \\
\hline U1-O4 & $1.741(4)$ & O1-U1-O1W & $64.08(11)$ & O3-U1-O1W & $90.29(8)$ \\
\hline U1-O1W & $2.438(3)$ & $\mathrm{O} 1-\mathrm{U} 1-\mathrm{O} 1 \mathrm{~W}^{i}$ & $115.90(11)$ & O4-U1-O1W & $89.71(8)$ \\
\hline $\mathrm{U} 1-\mathrm{O} 1 \mathrm{~W}^{i}$ & $2.438(3)$ & $\mathrm{O} 2-\mathrm{U} 1-\mathrm{O} 2^{i}$ & $178.68(14)$ & $\mathrm{O} 1 \mathrm{~W}-\mathrm{U} 1-\mathrm{O} 1 \mathrm{~W}^{i}$ & $179.42(16)$ \\
\hline \multicolumn{6}{|l|}{ Complex 2} \\
\hline U1-O3 & $2.473(6)$ & $\mathrm{O} 3-\mathrm{U} 1-\mathrm{O} 3^{i i}$ & $180.0(3)$ & O4-U1-O5 & $87.8(2)$ \\
\hline $\mathrm{U} 1-\mathrm{O}^{i i}$ & $2.473(6)$ & O3-U1-O4 & $52.4(2)$ & O4-U1-O5 ${ }^{i i}$ & $92.2(2)$ \\
\hline U1-O4 & $2.477(6)$ & $\mathrm{O} 3-\mathrm{U} 1-\mathrm{O} 4^{i i}$ & $127.6(2)$ & O4-U1-O1W & $63.84(18)$ \\
\hline $\mathrm{U} 1-\mathrm{O} 4^{i i}$ & $2.477(6)$ & O3-U1-O5 & $90.1(2)$ & $\mathrm{O} 4-\mathrm{U} 1-\mathrm{O} 1 \mathrm{~W}^{i i}$ & $116.16(18)$ \\
\hline U1-O5 & $1.771(6)$ & $\mathrm{O} 3-\mathrm{U} 1-\mathrm{O} 5^{i i}$ & $89.9(2)$ & $\mathrm{O} 5-\mathrm{U} 1-\mathrm{O}^{i i}$ & $180.000(1)$ \\
\hline $\mathrm{U} 1-\mathrm{O} 5^{i i}$ & $1.771(6)$ & O3-U1-O1W & $116.26(19)$ & O5-U1-O1W & $88.3(2)$ \\
\hline U1-O1W & $2.470(6)$ & $\mathrm{O} 3-\mathrm{U} 1-\mathrm{O} 1 \mathrm{~W}^{i i}$ & 63.74(19) & O5-U1-O1W ${ }^{i i}$ & $91.7(2)$ \\
\hline $\mathrm{U} 1-\mathrm{O} 1 \mathrm{~W}^{i i}$ & $2.470(6)$ & $\mathrm{O} 4-\mathrm{U} 1-\mathrm{O} 4^{i i}$ & $180.0(2)$ & $\mathrm{O} 1 \mathrm{~W}-\mathrm{U} 1-\mathrm{O} 1 \mathrm{~W}^{i i}$ & $180.000(1)$ \\
\hline
\end{tabular}

\# Symmetry transformation (i) $-\mathrm{x}, \mathrm{y}, 1.5-\mathrm{z}$; (ii) $2-\mathrm{x}, 2-\mathrm{y},-\mathrm{z}$

parameters of these $\mathrm{H}$-bonds for both the complexes are summarized in table 3.

\subsection{Crystal structure analysis of 1}

The part of the crystal lattice of $\mathbf{1}$ built around uranyl polyhedron is shown in figure 2 and crystal structure analysis shows the crucial role played by hydrogen bonding interactions, involving adenine and coordinated/non-coordinated water molecule, on overall crystal packing.

The monoanionic ligand $\mathbf{L 1}$ adopts anticonformation with respect to $\mathrm{C} 10-\mathrm{C} 11$, with a torsion angle of $174.8^{\circ}$ between adenine and carboxylate moiety. Thus, adenine residues are protruded in an

Table 3. Hydrogen bonding table for complexes $\mathbf{1}$ and $\mathbf{2} .^{\#}$

\begin{tabular}{|c|c|c|c|c|c|}
\hline $\mathrm{D}-\mathrm{H} \cdots \mathrm{A}$ & Symmetry of A & $d_{\mathrm{D}-\mathrm{H}}$ & $d_{\mathrm{H} \cdots \mathrm{A}}$ & $d_{\mathrm{D} \cdots \mathrm{A}}$ & $\angle \mathrm{D}-\mathrm{H} \cdots \mathrm{A}$ \\
\hline \multicolumn{6}{|l|}{ Complex 1} \\
\hline N6-H6A …O2W & $1 / 2-x, 1 / 2-y,-z$ & 0.86 & 2.19 & $3.032(6)$ & 166 \\
\hline N6-H6B $\cdots$ N3 & $\mathrm{x}, 1-\mathrm{y},-1 / 2+\mathrm{z}$ & 0.86 & 2.20 & $2.911(5)$ & 140 \\
\hline $\mathrm{O} 1 \mathrm{~W}-\mathrm{H} 1 \mathrm{~W} 1 \cdots \mathrm{O} 2 \mathrm{~W}$ & $-\mathrm{x}, 1-\mathrm{y},-\mathrm{z}$ & $0.79(3)$ & $1.99(3)$ & $2.771(5)$ & $168(5)$ \\
\hline 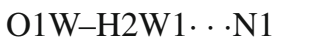 & $-1 / 2+x, 1 / 2+y, z$ & $0.80(5)$ & $1.95(5)$ & $2.741(6)$ & $170(5)$ \\
\hline $\mathrm{O} 2 \mathrm{~W}-\mathrm{H} 1 \mathrm{~W} 2 \cdots \mathrm{O} 1$ & $-\mathrm{x}, 1-\mathrm{y},-\mathrm{z}$ & $0.80(4)$ & $2.08(6)$ & $2.774(6)$ & $145(5)$ \\
\hline $\mathrm{O} 2 \mathrm{~W}-\mathrm{H} 2 \mathrm{~W} 2 \cdots \mathrm{N} 7$ & $\mathrm{x}, 1-\mathrm{y}, 1 / 2+\mathrm{z}$ & $0.81(4)$ & $2.01(4)$ & $2.796(5)$ & $165(8)$ \\
\hline $\mathrm{C} 8-\mathrm{H} 8 \cdots \mathrm{O} 3$ & $-\mathrm{x}, 2-\mathrm{y},-\mathrm{z}$ & 0.93 & 2.53 & $3.429(6)$ & 162 \\
\hline C11-H11A. . O3 & $-\mathrm{x}, 2-\mathrm{y},-\mathrm{z}$ & 0.97 & 2.55 & $3.497(5)$ & 164 \\
\hline \multicolumn{6}{|l|}{ Complex 2} \\
\hline $\mathrm{N} 3-\mathrm{H} 3 \cdots \mathrm{O} 2$ & $1-\mathrm{x},-\mathrm{y}, 1-\mathrm{z}$ & 0.86 & 1.96 & 2.793(9) & 162 \\
\hline $\mathrm{O} 1 \mathrm{~W}-\mathrm{H} 1 \mathrm{~W} \cdot \mathrm{O} 2$ & $1-\mathrm{x}, 1-\mathrm{y}, 1-\mathrm{z}$ & $0.82(8)$ & $2.09(8)$ & $2.822(9)$ & $148(9)$ \\
\hline $\mathrm{O} 1 \mathrm{~W}-\mathrm{H} 2 \mathrm{~W} \cdots \mathrm{O} 2$ & $1+\mathrm{x}, 1+\mathrm{y}, \mathrm{z}$ & $0.82(14)$ & $2.04(13)$ & $2.821(9)$ & $160(14)$ \\
\hline C5-H5 . .O1 & $-1+\mathrm{x}, \mathrm{y}, \mathrm{z}$ & 0.93 & 2.35 & $3.196(11)$ & 151 \\
\hline C6-H6. . O1W & $-1+\mathrm{x}, \mathrm{y}, \mathrm{z}$ & 0.93 & 2.58 & $3.409(10)$ & 148 \\
\hline C6-H6 . .O4 & $-1+x, y, z$ & 0.93 & 2.53 & $3.343(11)$ & 146 \\
\hline C8-H8B . . O5 & $-1+\mathrm{x}, \mathrm{y}, \mathrm{z}$ & 0.97 & 2.48 & $3.294(12)$ & 141 \\
\hline
\end{tabular}

${ }^{\#}$ Where ' $\mathrm{D}$ ' is donor and 'A' is acceptor; the bond lengths are in $(\AA)$ and angles are in $\left(^{\circ}\right)$ 


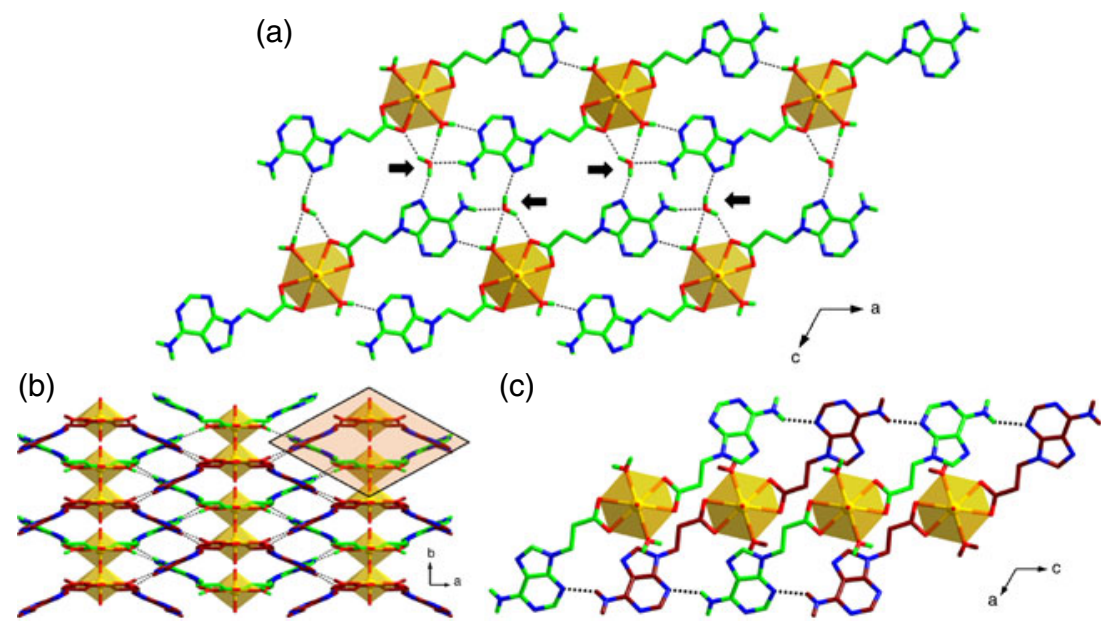

Figure 2. (a) Part of the crystal lattice of complex 1 showing hydrogen bonding network (solvent water molecule involved in quadruple $\mathrm{H}$-bond has been highlighted with arrow); (b) view of H-bonded 3-D crystal lattice showing orientation of different adenine residues, with respect to U(VI) polyhedron, highlighted with different colour; (c) view of highlighted portion in 'b' showing embedded adenine ribbon running along $c$-axis (colour code: green or brown-C or $\mathrm{H}$, blue-N, red-O and yellow-U).

outward direction, however they are not oriented in an anti-parallel fashion as they lie on the same side of the uranium polyhedra as can be seen from figure $2 \mathrm{~b}$. For the better understanding of various $\mathrm{H}$ bonding schemes, the lattice has been discriminated on the basis of orientation of adenine residues, with respect to the uranyl polyhedral, as represented with two different colour codes. This orientation of adenine residues allows hydrogen bonding interaction between N3 nitrogen and one of the exocyclic amino hydrogen i.e., N6-H6B $\cdots \mathrm{N} 3\left(d_{\mathrm{H} \cdots \mathrm{N}}=2.20 \AA\right)$ to take place. As a consequence, it results in an array of adenine ribbon-like arrangement, propagating along $c$-axis as shown in figure $2 c$. Adenine ribbons through Watson-Crick and Hoogsteen type base pairing have been reported, ${ }^{77-79}$ but in the present example the involvement of Watson-Crick or Hoogsteen face is not invoked for the generation of adenine ribbons. Instead, interplay of metal-coordination and hydrogen bonding interaction between exocyclic amino group and ring nitrogen is solely responsible for such architecture.

Significant interaction rendered by water molecules was also observed in the lattice. The coordinated aqua ligand O1W forms a pair of O1W-H2W1 $\cdots \mathrm{N} 1\left(d_{\mathrm{H} \cdots \mathrm{N}}=\right.$ $1.95(5) \AA)$ and O1W-H1W1 . . O 2W $\left(d_{\mathrm{H} \cdot \mathrm{O}}=1.99(3) \AA\right)$ hydrogen bonds with adenine residues and with noncoordinated lattice water molecules $(\mathrm{O} 2 \mathrm{~W})$, respectively. This results in an increase in the dimensionality of the crystal structure. It is interesting to note the role played by lattice water molecule $\mathrm{O} 2 \mathrm{~W}$ in complex $\mathbf{1}$, which is involved in multiple hydrogen bonding interactions (double donor and acceptor), as shown with a black arrow in figure $2 \mathrm{a}$. The $\mathrm{O} 2 \mathrm{~W}$ molecule acts as a donor for $\mathrm{O} 1$ oxygen of coordinated carboxylate group $\left(\mathrm{O} 2 \mathrm{~W}-\mathrm{H} 1 \mathrm{~W} 2 \cdots \mathrm{O} 1 ; d_{\mathrm{H} \ldots \mathrm{O}}=2.08(6) \AA\right)$ and adenine $\mathrm{N} 7$ nitrogen $\left(\mathrm{O} 2 \mathrm{~W}-\mathrm{H} 2 \mathrm{~W} 2 \cdots \mathrm{N} 7 ; d_{\mathrm{H} \cdots \mathrm{N}}=\right.$ 2.01(4) $\AA$ ), whereas it acts as an acceptor for coordinated aqua ligand $\mathrm{O} 1 \mathrm{~W}$ and remaining exocyclic amino hydrogen $\left(\mathrm{N} 6-\mathrm{H} 6 \AA \cdots \mathrm{O} 2 \mathrm{~W} ; d_{\mathrm{H} \cdots \mathrm{O}}=2.19 \AA\right.$ ). All these $\mathrm{H}$-bond interactions eventually generate a complex 3-D assembly while providing added strength to the lattice. Recently, the complexation behaviour of $\mathbf{L 1}$ ligand along with other modified adenine ligands towards $\mathrm{Co}$ (II) center was reported by us. ${ }^{80}$

It is indeed noteworthy to mention that both oxoatoms occupying the axial site of uranyl polyhedra, i.e., $\mathrm{O} 3$ and $\mathrm{O} 4$, are crystallographically non-equivalent and one of them (O3) displays weak $\mathrm{C}-\mathrm{H}$. . O interaction with $\mathrm{C} 8-\mathrm{H}$ of adenine and $\mathrm{C} 11-\mathrm{H}$ present in the linker. Probably, because of the electron affinity of the carboxylate group adjacent to this carbon atom (C11), its $\mathrm{H}$-atoms are relatively acidic and prone to be involved in $\mathrm{sp}^{3}-\mathrm{C}-\mathrm{H}$. O-M interactions. ${ }^{81}$ In complex $\mathbf{1}$, we observed that $\mathrm{O} 3$ atoms also acts as $\mathrm{H}$-bond acceptor for two $\mathrm{C}-\mathrm{H}$ sites $\left[\mathrm{C} 8-\mathrm{H}\left(d_{\mathrm{H} \cdots \mathrm{O}}=2.53 \AA\right)\right.$ and $\mathrm{C} 11-\mathrm{H}$ $\left.\left(d_{\mathrm{H} \cdots \mathrm{O}}=2.55 \AA\right)\right]$ as shown in figure 3 . The distances for these $\mathrm{C}-\mathrm{H}$. . O interactions are within the sum of their van der Waals radii of $1.72 \AA$. Such weak $\mathrm{C}-\mathrm{H}$... O interaction are significant for the stabilization of complex structures and they have been successfully 
(a)

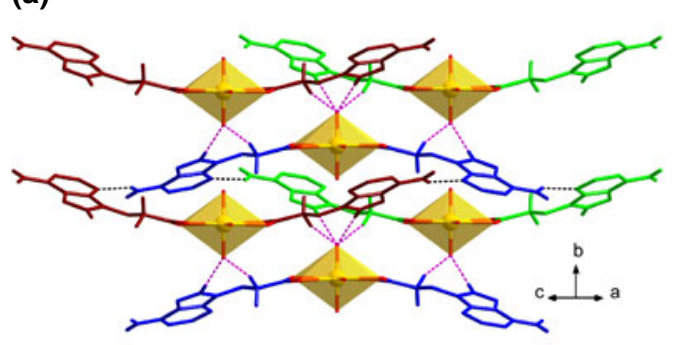

(b)

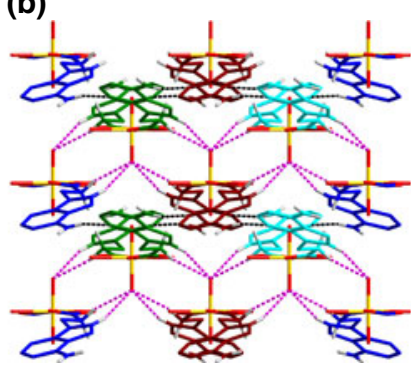

Figure 3. (a) Part of the crystal lattice of complex 1 showing $\mathrm{C}-\mathrm{H} \cdots \mathrm{O}$ interactions connecting one of the axial oxygen atom of the uranyl polyhedra with C8-H and $\mathrm{C} 11-\mathrm{H}$ atoms as shown with pink fragmented bonds; (b) view of the crystal lattice close to $a$-axis showing 2-D network along (011) plane.

exploited in crystal engineering and material science. ${ }^{82-85}$ Together with $\mathrm{N}-\mathrm{H} \cdot \cdots \cdot \mathrm{N}$ interactions, this $\mathrm{C}-\mathrm{H} \cdot \cdot \cdot \mathrm{O}$ interaction allows connectivity between different $\mathrm{L}-\mathrm{M}-\mathrm{L}$ units consequently resulting in a $2-\mathrm{D}$ network along the (011) plane (figure 3b). The other crystal stabilizing interaction comes from $\pi-\pi$ stacking between adenine residues with a centroid separation of $3.37 \AA$.

\subsection{Crystal structure analysis of 2}

Part of the crystal lattice of $\mathbf{2}$ is shown in figure 4 where uracil moieties and coordinated aqua ligands

(a)

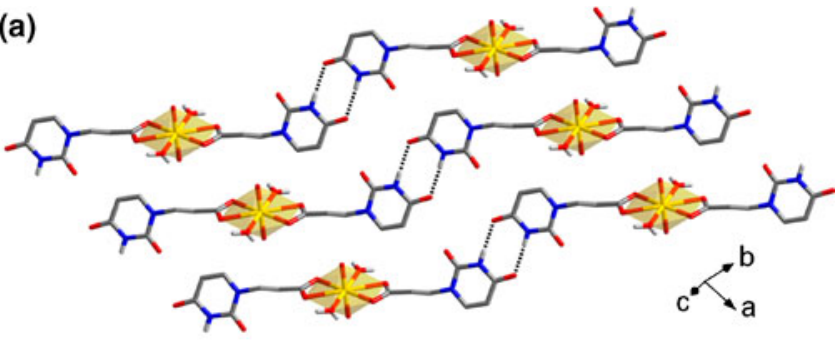

(b)

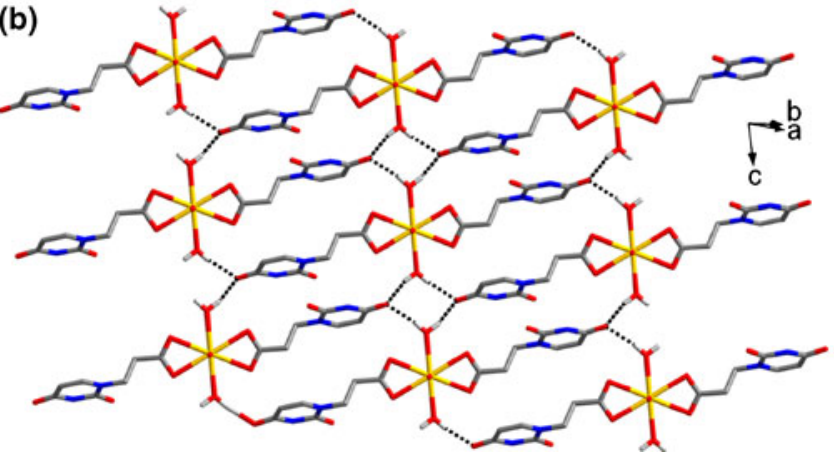

Figure 4. (a) Self-association of uracil moiety via $\mathrm{H}$ bonding in case of 2; (b) Interaction between uracil moiety and coordinated aqua ligands along $c$-axis (H-bonds are shown with fragmented black bonds) (colour code: gray-C; light gray-H, blue-N, red-O and yellow-U). decipher intricate $\mathrm{H}$-bonding schemes to influence overall supramolecular assembly. The monoanionic ligand L2 adopts anti-conformation along C7-C8 bond with a torsion angle of $171.9^{\circ}$, between uracil and carboxylate moiety, similar to 1. Careful analysis of the crystal lattice shows that uracil moieties of different L-M-L species self-associate via strong N3-H3 $\cdots \mathrm{O} 2\left(d_{\mathrm{H} \cdots \mathrm{O}}=\right.$ $1.96 \AA$ ) interaction through the Watson-Crick face, in a phenomenon known for the uracil moiety, ${ }^{86,87}$ which eventually results in the formation of 1D polymeric species as depicted in figure $4 \mathrm{a}$. Interestingly, the coordinated aqua ligand interacts with $\mathrm{O} 2$ oxygen atoms of different uracil moieties along $c$-axis as shown in figure $4 \mathrm{~b}$. The donor-acceptor distances for both the hydrogen atoms present on the aqua ligand, $\mathrm{O} 1 \mathrm{~W}-\mathrm{H} 1 \mathrm{~W} \cdot \mathrm{O} 2^{i}$ $(\mathrm{i}=1-\mathrm{x}, 1-\mathrm{y}, 1-\mathrm{z})$ and $\mathrm{O} 1 \mathrm{~W}-\mathrm{H} 2 \mathrm{~W} \cdot \mathrm{O} 2^{i i}(\mathrm{ii}=1+\mathrm{x}$, $1+\mathrm{y}, \mathrm{z})$, are almost similar with $d_{O \ldots O}=2.82 \AA$ indicating comparable interactions from both the sides. Thus, O2 oxygen simultaneously acts as an H-bond acceptor for three different centers, where two are aqua ligands and the third one is uracil $\mathrm{NH}$ hydrogen. The $\mathrm{N} 3-\mathrm{H} \cdots \mathrm{O} 2$ and $\mathrm{O} 1 \mathrm{~W}-\mathrm{H}$... $\mathrm{O} 2$ interactions are almost perpendicular to each other as visualized by comparing figure $4 \mathrm{a}$ and figure $4 \mathrm{~b}$.

Further stabilization of the crystal lattice in $\mathbf{2}$ comes from various $\mathrm{C}-\mathrm{H}$... $\mathrm{O}$ interactions similar to $\mathbf{1}$. Notably, the remaining carbonyl oxygen (O1) of uracil moiety interacts with $\mathrm{C} 5-\mathrm{H}\left(d_{\mathrm{C} 5-\mathrm{H} 5 \cdots \mathrm{O} 1}=2.35 \AA\right)$, which results in the formation of neatly packed uracil ribbon structure running along $a$-axis, as shown in figure 5 . An interesting aspect of the lattice structure concerns formation of a homouracil tetrad structure where four uracil moieties interact with each other by utilizing $\mathrm{N} 3-\mathrm{H}$ and $\mathrm{C} 5-\mathrm{H}$ as hydrogen bond donors, while pyrimidine carbonyl oxygens $\mathrm{O} 1$ and $\mathrm{O} 2$ act as hydrogen bond acceptors (figure 5). ${ }^{88,89}$ The L-M-L species constituting the tetrad structures are further reinforced 


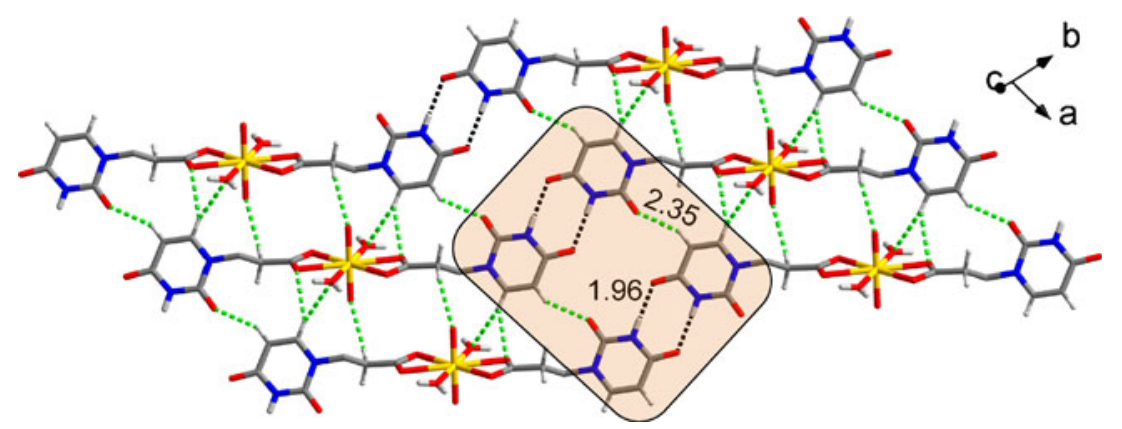

Figure 5. Crystal lattice of $\mathbf{2}$ showing neatly packed uracil ribbons running along $a$-axis, with an embedded homouracil tetrad structure (boxed); $\mathrm{C}-\mathrm{H} \cdots \mathrm{O}$ interactions are shown with green fragmented bonds (bond lengths are in $\AA$ ).

through a variety of C-H. . O interactions as shown in figure 5 (also see table 3). Thus, uracil-uracil interaction to generate uracil ribbon extends the lattice in two-dimensions close to the (110) plane, whereas the participation of aqua ligands in H-bonding further increases the dimensionality to generate a 3-D network.

\section{Conclusion}

In conclusion, we have synthesized and investigated uranyl complexes of carboxylic acid functionalized adenine and uracil analogues. This exercise expands the coordination space provided by unmodified adenine and uracil moieties and relies on stable interactions achieved with U(VI) and carboxylate functionality. It was observed that $\mathrm{H}$-bonding schemes offered by nucleobase analogs, in addition to the presence of carboxylate groups supporting metal coordination, results in complex 3D-crystal lattice structures. An interesting interplay of variety of $\mathrm{H}$-bonding interactions also generates embedded nucleobase ribbons as a part of larger three-dimensional framework supported by weak interactions.

\section{Supporting information}

$\mathrm{X}$-ray crystallographic data in CIF format are given. CCDC contains the supplementary crystallographic data for this paper with a deposition number of CCDC 827791 (complex1) and 827792 (complex 2). Copies of this information can be obtained free of charge on application to CCDC, 12 Union Road, Cambridge CB21EZ, UK. [Fax: +44-1223/336-033; e-mail: deposit@ccdc.cam.ac.uk].

\section{Acknowledgements}

We thank Single Crystal CCD X-ray facility at Indian Institute of Technology (IIT), Kanpur; and Council of Scientific Industrial Research (CSIR), New Delhi, India for SPM Fellowship to JK. This work was supported by an Indo-Spain DST project and SV acknowledges this support.

\section{References}

1. Natale D and Mareque-Rivas J C 2008 Chem. Commun. 8425

2. Desiraju G R 2007 Angew. Chem. Int. Ed. 468342

3. Roesky H W and Andruh M 2003 Coord. Chem. Rev. 23691

4. Eddaoudi M, Moler D B, Li H, Chen B, Reineke T M, O'Keeffe M and Yaghi O M 2001 Acc. Chem. Res. 34 319

5. Subramanian S and Zaworotko M J 1994 Coord. Chem. Rev. 137357

6. Gellrich U, Huang J, Seiche W, Keller M, Meuwly M and Breit B 2011 J. Am. Chem. Soc. 133964

7. Yamanaka M, Toyoda N and Kobayashi K 2009 J. Am. Chem. Soc. 1319880

8. Langner A, Tait S L, Lin N, Chandrasekar R, Ruben M and Kern K 2008 Angew. Chem. Int. Ed. 478835

9. McKinlay R M, Thallapally P K, Cave G W V and Atwood J L 2005 Angew. Chem. Int. Ed. 445733

10. Maji T K, Matsuda R and Kitagawa S 2007 Nat. Mater. 6142

11. Deifel N P and Cahill C L 2011 Chem. Commun. 47 6114

12. Mansfeld U, Hager M D, Hoogenboom R, Ott C, Winter A and Schubert U S 2009 Chem. Commun. 3386

13. Balamurugan V, Jacob W, Mukherjee J and Mukherjee R 2004 Cryst. Eng. Comm. 6396

14. Baburin I A, Blatov V A, Carlucci L, Ciani G and Proserpio D M 2008 Cryst. Eng. Comm. 101822

15. Melegari M, Massera C, Ugozzoli F and Dalcanale E 2010 Cryst. Eng. Comm. 122057 
16. Amo-Ochoa P, Miguel P J S, Castillo O and Zamora F 2007 Cryst. Eng. Comm. 9987

17. Stephenson M D, Prior T J and Hardie M J 2008 Cryst. Growth Des. 8643

18. Duong A, Metivaud V, Maris T and Wuest J D 2011 Cryst. Growth Des. 112026

19. Sun W -W, Cheng A -L, Jia Q -X and Gao E -Q 2007 Inorg. Chem. 46, 5471

20. Friščić T, Meštrović E, Šamec D Š, Kaitner B and Fábián L 2009 Chem- Eur. J. 1512644

21. Rajput L, Sarkar M and Biradha K 2010 J. Chem. Sci. 122707

22. Ghoshal D and Maji T K 2010 J. Chem. Sci. 122801

23. Taş M and Büyükgüngör O 2009 J. Chem. Sci. 121267

24. Baudron S A, Salazar-Mendoza D and Hosseini M W 2009 Cryst. Eng. Comm. 111245

25. Férey G 2008 Chem. Soc. Rev. 37191

26. Beatty A M 2003 Coord. Chem. Rev. 246131

27. Desiraju G R 2003 J. Mol. Struct. 6565

28. Shi L, Wang X, Sandoval C A, Li M, Qi Q, Li Z and Ding K 2006 Angew. Chem. Int. Ed. 454108

29. Garcia-Zarracino R and Hopfl H 2004 Angew. Chem. Int. Ed. 431507

30. Takaoka K, Kawano M, Hozumi T, Ohkoshi S-i and Fujita M 2006 Inorg. Chem. 453976

31. Briceño A, Hill Y, González T and Díaz de Delgado G 2009 Dalton Trans. 1602

32. Custelcean R 2008 Chem. Commun. 295

33. Custelcean R, Moyer B A, Bryantsev V S and Hay B P 2006 Cryst. Growth Des. 6555

34. Custelcean R, Moyer B A and Hay B P 2005 Chem. Commun. 5971

35. Custelcean R, Haverlock T J and Moyer B A 2006 Inorg. Chem. 456446

36. Piepenbrock M -O M, Anderson K M, Sansam B C R, Clarke N and Steed J W 2009 Cryst. Eng. Comm. 11118

37. Sekiya R, Nishikiori S-i and Kuroda R 2009 Cryst. Eng. Comm. 112251

38. Saenger W 1984 Principles of nucleic acid structure (New York: Springer)

39. Lippert B 1996 Interaction of metal ions with nucleotides, nucleic acids and their constituents, in: Sigel A and Sigel H (eds), 1996 Metal Ions in Biological System, vol. 32, New York: Marcel; Dekker

40. Lippert B 2000 Coord. Chem. Rev. 200-202 487

41. Berners-Price S J and Sadler P J 1996 Coord. Chem. Rev. 1511

42. Verma S, Mishra A K and Kumar J 2010 Acc. Chem. Res. 4379

43. Pandey M D, Mishra A K, Chandrasekhar V and Verma S 2010 Inorg. Chem. 492020

44. Kumar J, Awasthi S and Verma S 2010 Cryst. Growth Des. 103555

45. Mishra A K and Verma S 2010 Inorg. Chem. 493691

46. Mishra A K and Verma S 2010 Inorg. Chem. 498012

47. Kumar J and Verma S 2009 Inorg. Chem. 486350

48. Singh P, Toma F M, Kumar J, Venkatesh V, Raya J, Prato M, Verma S and Bianco A 2011 Chem-Eur. J. 176772

49. Singh P, Kumar J, Toma F M, Raya J, Prato M, Fabre B, Verma S and Bianco A 2009 J. Am. Chem. Soc. 131 13555
50. Singh P, Lamanna G, Menard-Moyon C, Toma F M, Magnano E, Bondino F, Prato M, Verma S and Bianco A 2011 Angew. Chem., Int. Ed., doi:anie.201102976

51. Pearson G R 1963 J. Am. Chem. Soc. 853533

52. Choppin G R, Rizkalla E N and Sullivant J C 1987 Inorg. Chem. 262318

53. Hnatejko Z, Lis S, Stryşa Z and Starynowicz P 2010 Polyhedron 292081

54. Lis S, Meinrath G, Glatty Z and Kubicki M 2010 Inorg. Chim. Acta 3633847

55. Yasodhai S and Govindarajan S 2002 J. Therm. Anal. Calorim. 67679

56. Giesting P A and Burns P C 2006 Crystallogr. Rev. 12 205

57. Severance R C, Vaughn S A, Smith M D and Zur Loye H-C 2011 Solid State Sci. 131344

58. Rowland C E and Cahill C L 2010 Inorg. Chem. 49 6716

59. Liao Z -L, Li G -D, Wei X, Yu Y and Chen J -S 2010 Eur. J. Inorg. Chem. 3780

60. Ji C, Li J, Li Y and Zheng H 2010 Inorg. Chem. Commun. 131340

61. Thuéry P 2010 Cryst. Eng. Comm. 121905

62. Thuéry P 2010 Cryst. Growth Des. 102061

63. Liu T, Duan G and Zeng Z 2009 J. Coord. Chem. 62 2203

64. Masci B and Thuéry P 2008 Cryst. Growth Des. 8 1689

65. Knope K E and Cahill C L 2007 Inorg. Chem. 466607 references are there in

66. Dalla Cort A, Mandolini L and Schiaffino L 2008 J. Org. Chem. 739439

67. van Axel Castelli V, Dalla Cort A, Mandolini L, Pinto V and Schiaffino L 2007 J. Org. Chem. 725383

68. van Axel Castelli V, Dalla Cort A, Mandolini L and Reinhoudt D N 1998 J. Am. Chem. Soc. 12012688

69. Liao Z -L, Li G -D, Bi M -H and Chen J-S 2008 Inorg. Chem. 474844

70. Xia Y, Wang K -X and Chen J -S 2010 Inorg. Chem. Commun. 131542

71. Yu Z -T, Liao Z -L, Jiang Y -S, Li G -H and Chen J -S 2005 Chem. Eur. J. 11, 2642

72. Das S, Madhavaiah C, Verma S and Bharadwaj P K 2006 Inorg. Chim. Acta 359548

73. Van Horn J D and Huang H 2006 Coord. Chem. Rev. 250 765

74. Brucker 1999 SAINT+ version 6.02 Bruker AXS inc, Madison, WI (USA)

75. Sheldrick G M 2000 SADABS 2.0 (Germany: University of Göttingen)

76. Sheldrick G M 1997 SHELXL-97: Program for the refinement of crystal structures (Germany: University of Göttingen)

77. Dobrzynska D and Jerzykiewicz L B 2004 J. Am. Chem. Soc. 12611118

78. Zierkiewicz W, Michalska D and Hobza P 2010 Phys. Chem. Chem. Phys. 122888

79. Kumar J, Purohit C S and Verma S 2008 Chem. Commun. 2526

80. Mishra A K, Kumar J, Khanna S and Verma S 2011 Cryst. Growth Des. 111623 
81. Du M and Li C -P 2006 Inorg. Chim. Acta 3591690

82. Wahl M C and Sundaralingam M 1997 Trends Biochem Sci. 2297

83. Scheiner S 2011 Phys. Chem. Chem. Phys. 1313860

84. Desiraju G R 2005 Chem. Commun. 2995

85. Sato H, Murakami R, Padermshoke A, Hirose F, Senda K, Noda I and Ozaki Y 2004 Macromolecules 37 7034
86. Patwa A N, Gonnade R G, Kumar V A, Bhadbhade M M and Ganesh K N 2010 J. Org. Chem. 758705

87. Ruf M, Weis K and Vahrenkamp H 1997 Inorg. Chem. 362130

88. Meyer M, Steinke T, Brandl M and Sühnel J 2001 J. Comput. Chem. 22109

89. Gu J and Leszczynski J 2001 J. Phys. Chem. A 105 10366 